\title{
Long-term mechanical reliability of ceramic thick-film circuits and mechanical sensors under static load
}

\author{
Thomas Maeder*, Caroline Jacq, Peter Ryser \\ Laboratoire de Production Microtechnique, École Polytechnique Fédérale de Lausanne (EPFL), Station 17, \\ CH-1015 Lausanne, Switzerland \\ *http://lpm.epfl.ch / thomas.maeder@epfl.ch \\ Original version: Sensors and Actuators A, 2012 \\ Permanent link: http://hdl.handle.net/10.1016/j.sna.2012.05.031
}

\begin{abstract}
In this work, we study the long-term mechanical strength under static load - i.e. static fatigue performance or resistance to subcritical crack growth - of ceramic thick-film circuits, namely how the static fatigue of the substrate is affected by the presence of thick-film compositions on the surface subjected to tensile stress. Three substrate materials were compared: standard $96 \%$ alumina $\left(\mathrm{Al}_{2} \mathrm{O}_{3}\right)$ and two grades of high-strength zirconia-toughened alumina (ZTA). The tested thick-film compositions included Ag- and Au-based conductors, a multilayer dielectric, resistors, and an overglaze, alone or in combination. The tests were carried out by applying a nominally constant load on cantilevers, at room temperature and in nominally $100 \%$ humidity, with stress data extracted according to log-normal and Weibull statistics. In the blank state, both ZTA grades exhibit higher short-term strength than $96 \% \mathrm{Al}_{2} \mathrm{O}_{3}$, as well as much higher resistance to static fatigue. However, many thick-film compositions are found to degrade the static fatigue performance, with higher-strength ZTA being in general more affected. This implies that thick-film materials used in circuits under high mechanical stress, such as force and pressure sensors and devices operating in harsh environments, must be carefully chosen and placed in order to ensure reliable long-term operation.
\end{abstract}

Keywords: thick-film technology; ceramic substrates and circuits; piezoresistive sensors; SCG; static fatigue

\section{Introduction}

Ceramic circuits are widely used for high-reliability applications in electronics, electronics packaging and sensors, as they allow - depending on materials and design - excellent thermal, dimensional and chemical stability, high thermal conductivity, thermal expansion matching to semiconductors, high strength and good 3D structurability. Typical technologies for creating circuits on ceramics are thick-film, thin-film, low-temperature cofired ceramic (LTCC, a development of thick-film), high-temperature cofired ceramic (HTCC, mainly used for ceramic packages) and direct bonded copper (DBC) [1-6]. Available ceramic substrates include 96\% thickfilm grade alumina $\left(\mathrm{Al}_{2} \mathrm{O}_{3}\right.$ with ca. $4 \%$ glassy phase), high-purity $(>99 \%)$ fine-grain thin-film grade $\mathrm{Al}_{2} \mathrm{O}_{3}$, zirconia-toughened alumina (ZTA), yttrium-stabilised zirconia (YSZ; $\mathrm{ZrO}_{2}$ with ca. $\left.3 \% \quad \mathrm{Y}_{2} \mathrm{O}_{3}\right)$, aluminium nitride $(\mathrm{AlN})$, beryllium oxide $(\mathrm{BeO})$ and proprietary LTCC compositions.

Thick-film and LTCC technologies are widely applied to force and pressure sensors [7], based on the good piezoresistive properties of thick-film resistors [8], and this requires high-strength substrates to achieve a high output signal. Although very high sensing performance has been in principle demonstrated for metallic substrates [9], serious compatibility problems still must be 
solved, requiring in practice non-standard low-temperature processes [10]. Therefore, ceramic substrates are more practical for many purposes, such as simple low-cost force sensors [11-14] or integration of pressure sensing within a 3D fluidic circuit [15-17].

To date, standard $96 \%$ alumina is - in spite of its mediocre maximum allowable strain - the most commonly used ceramic substrate for thick-film piezoresistive sensors due to its compatibility with thick-film technology and low cost. LTCC, although not much better in principle [12], allows 3D integration, which makes it an important substrate. High-strength alternatives to alumina are YSZ and ZTA. While YSZ allows higher signal, its high cost can be prohibitive, and its high thermal expansion and different chemistry give rise to large shifts in resistor properties vs. alumina, and ZTA appears more favourable overall [18]. Also, in the important application of power electronics substrates such as DBC, both static and relatively slow dynamic stresses arise from the thermal mismatch between $\mathrm{Cu}$ and $\mathrm{Al}_{2} \mathrm{O}_{3} / \mathrm{ZTA}$, as well as from thermal gradients during operation. Further (quasi-static) stresses in ceramic circuits and packages can arise from sources such as adhesive bonding and potting with hard compounds such as epoxy resins, soldering and mechanical fastening. As ceramic circuits are often expected to perform critical functions in harsh environments, this work has important implications, beyond sensors, for the reliability of thick-film devices.

Although ceramic substrates may have high strength levels, their inherent brittleness makes them susceptible to mechanical shock, stress concentrations and flaws. In a previous study [18], shortterm strength of alumina, YSZ and ZTA was shown to be strongly reduced by processing flaws induced by laser scoring and cutting, and also by some thick-film compositions, notably fritted $\mathrm{Ag}: \mathrm{Pd}$ conductors. On the other hand, complete thick-film piezoresistive cantilever load cells, made using $\mathrm{Au}$ conductor, piezoresistor and overglaze layers, apparently retained the original substrate strength in the short term for the three tested substrates, 96\% alumina, YSZ and ZTA.

Short-term strength, however, is not a safe indicator of stability; another important cause of failure for glass and ceramics is static fatigue (also called subcritical / slow crack growth, SCG). This is mostly due, under ambient conditions, to stress corrosion by water (vapour or immersion) [19]. Thick-film grade $96 \%$ alumina, which contains ca. $4 \%$ intergranular glassy phase, is also susceptible to SCG in water [20]. This was also observed by us for $96 \%$ alumina tested in humid air, but the effect was very low in blank YSZ and ZTA, presumably due to the essential absence of glassy phase in these materials [21]. However, this study also showed that the above-mentioned cantilever load cells (with thick-film layers), while matching the strength of the blank substrates in the short term, were significantly more susceptible to SCG in humid air, and that this effect was much more pronounced with the high-strength YSZ and ZTA substrates. Again, this result can be rationalised by the presence of SCG-sensitive glassy materials (resistor and overglaze layers) on the surface subjected to tensile strain that can act as crack initiators for the whole substrate. This hypothesis is also confirmed by the high SCG sensitivity of LTCC - which also has glassy phase observed by us [12].

Based on these results, a more systematic study was initiated [22] to evaluate the effect of thickfilm compositions on SCG failure of $96 \% \mathrm{Al}_{2} \mathrm{O}_{3}$, and two grades of ZTA. This work is completed in the present paper, with final results on a much more comprehensive set of materials and taking into account surviving samples. 


\section{Experiments}

Three substrate materials were used (Table 1): standard thick-film grade $96 \%$ alumina (S00, Kyocera A-476) and two experimental grades of ZTA (S01 and S03) provided by CeramTec AG, which specified them to be "similar" to the commercial "Rubalit HSS" grade introduced in the meantime.

Overall, sample preparation and testing was identical with the previous study [22]. The thick-film materials, listed in Table 2, were deposited onto cantilevers in strips by screen printing according to the layout shown in Fig. 1, and fired at the indicated temperature (10 min dwell), in dry air according to a standard 45 min (total) cycle. A $2^{\text {nd }}$ printing and firing cycle was made for the "overglazed" samples, with a slightly larger printed area completely covering the $1^{\text {st }}$ layer. After firing, the individual cantilevers were singulated by laser scoring and breaking, with the scored side at the bottom, e.g. in compression during testing, to avoid weakening by the flaws created by scoring [18].

SCG testing was carried out as before [22], with the film-covered side under tensile stress, at room temperature $\left(22 \pm 2^{\circ} \mathrm{C}\right)$ in close to $100 \%$ relative humidity $(\mathrm{RH})$, with samples stored at least overnight in this environment prior to loading. Each cantilever was mounted onto a base (Fig. 2), and a constant force was applied with a vertical pushrod loaded with weights, and the time to failure was monitored. Vibrations were minimised by mounting the weights on springs and cushioning the setup with plastic foam (Fig. 3). The average number of samples per individual series was 57.

\section{Calculations - data analysis}

\subsection{SCG degradation of failure stress}

The expected long-term failure stress caused by SCG can be fitted by the following relation $[19,23,24]$ :

$$
\frac{\sigma}{\sigma_{0}}=\left(\frac{t}{t_{0}}\right)^{-\frac{1}{n}}, \text { for linear fitting: } \ln \sigma=\ln \sigma_{0}-\frac{1}{n} \cdot \ln \frac{t}{t_{0}}
$$

Table 1. Tested substrates.

\begin{tabular}{lll}
\hline Code & Description & Thickness $\boldsymbol{h}$ \\
\hline S00 & 96\% alumina (+4\% glassy phase), Kyocera A-476 & $0.25 \mathrm{~mm}$ \\
S01 & ZTA HSS2-14-02-003 & $0.33 \mathrm{~mm}$ \\
S03 & ZTA HSS4-38/3 & $0.30 \mathrm{~mm}$ \\
\hline
\end{tabular}

ZTA: Experimental grades of zirconia-toughened alumina from CeramTec AG, Germany 
The "reference time" $t_{0}$ can assume any arbitrary value, and is taken here to be $1 \mathrm{~s}$. With such a short time, the stress $\sigma_{0}$ is essentially an extrapolated short-term failure stress, and in practice lies reasonably close to the average value obtained from short-term mechanical testing. The reader is referred to the more detailed discussions in the above-mentioned references. The other parameter, the time exponent $n$, characterises the SCG effect on strength, with materials relatively immune to SCG having high values of $n$.

\subsection{Distribution of failure stress and time}

In strength of brittle materials such as ceramics and glasses, the Weibull distribution function is widely used. This function $\mathrm{W}$, normally used for short-time testing, can be extended for SCG to give the failure probability $F$ as a function of the stress $\sigma$ and time $t$ [23]:

$$
F(\sigma, t)=\mathrm{W}_{\sigma_{W}, m^{*}}(\sigma, t)=1-\exp \left[-\left(\frac{\sigma}{\sigma_{W}}\right)^{m^{*}}-\left(\frac{t}{t_{0}}\right)^{\frac{m^{*}}{n}}\right], \text { where } m^{*}=m \cdot \frac{n}{n-2}
$$

Table 2. Tested thick-film materials.

\begin{tabular}{llllcc}
\hline $\begin{array}{l}\text { Code } \\
\text { w/o } \\
\text { overglaze }\end{array}$ & $\begin{array}{l}\text { with } \\
\text { overglaze }\end{array}$ & Description & $\begin{array}{l}\text { Thick-film } \\
\text { paste }^{\mathrm{a}}\end{array}$ & $\begin{array}{c}\text { Thick- } \\
\text { ness } \\
{[\mu \mathrm{m}]^{\mathrm{b}}}\end{array}$ & $\begin{array}{c}\text { Firing } \\
\text { temp. } \\
{\left[{ }^{\circ} \mathrm{C}\right]^{\mathrm{c}}}\end{array}$ \\
\hline V00 & V10/V11 & Blank (V00) or overglaze only & & - & - \\
V01 & - & Ag, low-firing, fritted & ESL 590G & 12 & 500 \\
V02 & V12 & Ag, standard, mixed bonded & ESL 9912A & 12 & 850 \\
V03 & V13 & AgPd, $\approx 3: 1$, standard, fritted & ESL 9635B & 12 & 850 \\
V04 & V14 & Ag(Pd+Pt), $\approx$ :1, fritless & ESL 9562 & 12 & 850 \\
V05 & V15 & Au, thin, mixed bonded & ESL 8837D & 2 & 850 \\
V06 & V16 & Au, standard & DP 5715 & 8 & 850 \\
V07 & V17 & 10 k $\Omega$ resistor, standard & DP 2041 & 15 & 850 \\
V08 & V18 & $10 \mathrm{k} \Omega$ resistor, low-firing & ESL 3114 & 15 & 630 \\
V09 & - & Multilayer dielectric & ESL 4913 & 40 & 850 \\
V10 & - & Overglaze (fired matt) & ESL G-481 & 8 & 580 \\
V11 & - & Overglaze (fired smooth) & ESL G-481 & 8 & 630 \\
\hline
\end{tabular}

a) Manufacturers: ESL = ElectroScience Laboratories (USA); DP = DuPont (USA)

b) Typical thicknesses of $1^{\text {st }}$ layer

c) Firing temperature is for basic layer; overglaze on other layers $=$ V11 (ESL G-481 fired at $630^{\circ} \mathrm{C}$ )

d) Printed and fired twice 


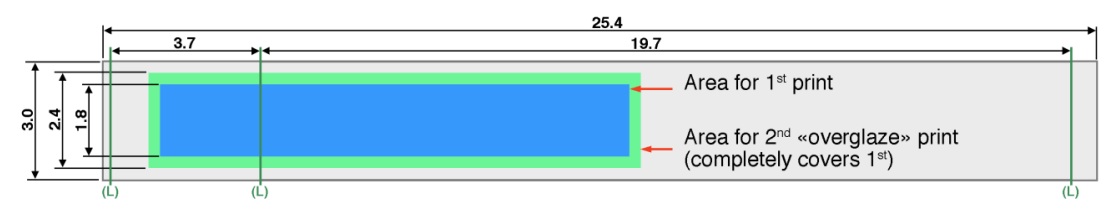

Figure 1. Layout of the samples, with (L) designating the position of the load.

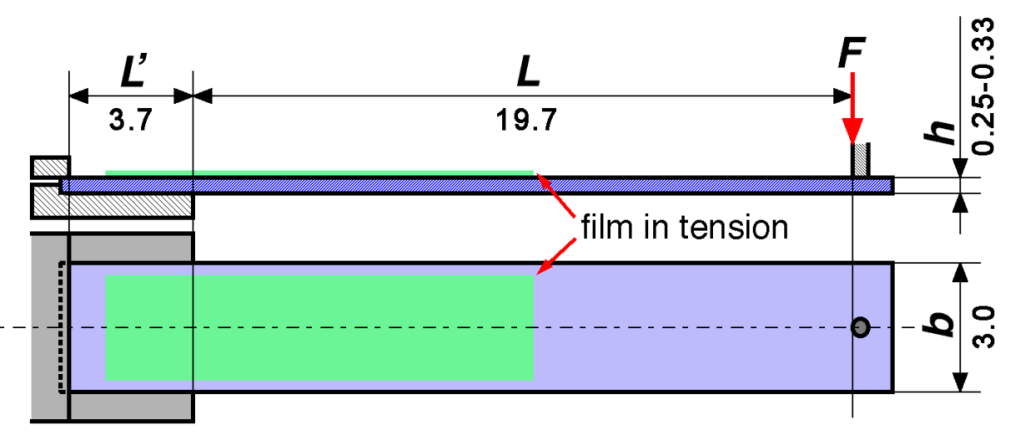

Figure 2. Cantilever sample mount.

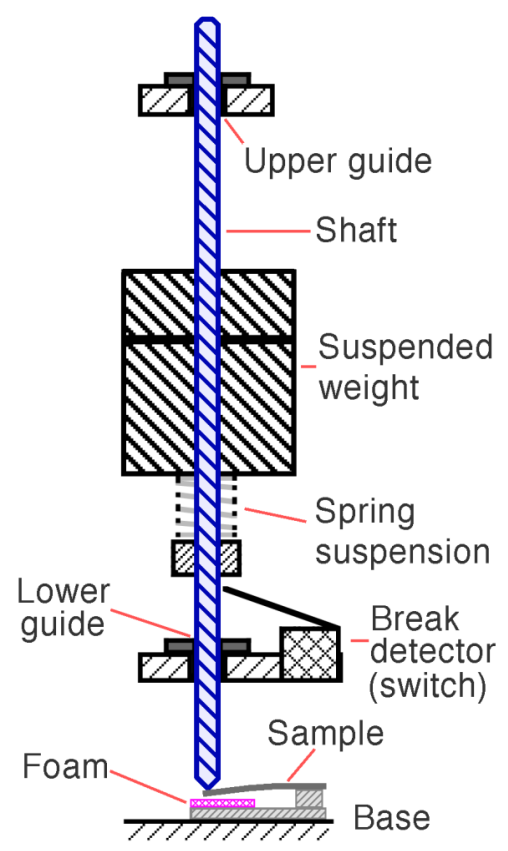

Figure 3. Testing jig for one cantilever.

The scale parameter $\sigma_{W}$ determines the typical failure stress, and the shape parameter (stress exponent) $m^{*}$ gives the degree of spread, high values of $m^{*}$ indicating a narrow failure stress range. Given the usually high values of $n(>20)$, the stress exponents $m$ (for inert strength) and $m^{*}$ (SCG) are almost equal.

Another commonly used function is the log-normal distribution, where the failure probability $F$ vs. the logarithm of $\sigma$ follows a normal distribution, which can be expressed with the standard normal cumulative distribution function $\Phi$, and extended for SCG [24] in a similar manner to (2), with corresponding parameters $\sigma_{0}$ and $\Delta$ (analogues to $\sigma_{W}$ and $m^{*}$ ):

$$
F(\sigma, t)=\Phi\left(\frac{1}{\Delta} \cdot \ln \frac{\sigma}{\sigma_{0}}+\frac{1}{\Delta \cdot n} \cdot \ln \frac{t}{t_{0}}\right)
$$

Here, $\sigma_{0}$ gives the geometric mean of the stress for $t=t_{0}$, and (1) can be used to calculate the expected geometric mean of the stress at any time $t$. The logarithm of its geometric standard deviation (LGSD) is constant and given by $\Delta$, with $\Delta \cdot n$ conversely giving the LGSD of failure time at any stress [24]. For relatively tight distributions (LGSD $<<1$ ), the log-normal distribution is essentially equivalent to a normal one, with LGSD approximately equal to the coefficient of variation $\left(\Delta \cong C_{v}\right)$. This is in most cases true for the failure stress, but not for the failure time, where the distribution is very broad due to the usually large $n$ values. 


\subsection{Extraction of the parameters}

First, the parameters for (1), $\sigma_{0}$ and $n$, are extracted by linear regression analysis of the data, given by failure stress and time data pairs $\left(\sigma_{i}, t_{i}\right)$. Thus, for a given failure stress or time, the corresponding expected failure time $t^{*}$ or stress $\sigma^{*}$ will be given, at constant failure probability $F$, respectively by:

$$
t^{*}=t_{0} \cdot \exp \left(-n \cdot \ln \frac{\sigma}{\sigma_{0}}\right) \text { or } \sigma^{*}=\sigma_{0} \cdot \exp \left(-\frac{1}{n} \cdot \ln \frac{t}{t_{0}}\right)
$$

For the log-normal distribution, the above calculated values are maximum-likelihood ones, and also correspond to $F=0.5$. The LGSD of the failure stress $\Delta$ is calculated by computing the standard residual error, i.e. the standard deviation of $\ln \left(\sigma / \sigma^{*}\right)$ for the data series.

In order to extract the Weibull stress distribution parameters for a series of $N$ samples, we sort the series in ascending order of short-time stress, calculating the "experimental" failure probability $F_{i}$ for a given sample, and rewriting (2), which allows extraction of $m^{*}$ and $\sigma_{W}$ by linear regression:

$$
F_{i}=\frac{i}{N+1} \text { and } \ln [-\ln (1-F)]=-m^{*} \cdot \ln \sigma_{W}+m^{*} \cdot\left(\ln \sigma+\frac{1}{n} \cdot \ln \frac{t}{t_{0}}\right)
$$

In this work, we mainly use the log-normal distribution; a comparison is given, for similar LGSD, in Appendix A.

\subsection{Treatment of samples that withstood loading}

In some sets, a small minority (ca. 1\%) of the samples, having not failed within a reasonable time $t_{\text {in }}$ under an initial stress $\sigma_{i n}$, were subjected to loading at a higher final stress $\sigma$. In this case, the stresscorrosion damage due to the initial loading was accounted for by adding an equivalent time $\Delta t_{e q}$ to the observed failure time under final stress $t$ :

$$
\Delta t_{e q}=t_{i n} \cdot\left(\frac{\sigma_{i n}}{\sigma}\right)^{n}, \text { where } \sigma_{i n} / \sigma<1
$$

At the end of the tests, a small proportion (also ca. 1\%) of samples were simply stopped. This requires a somewhat more complicated treatment. Assuming here a log-normal distribution, the distribution of the failure probability vs. time is a priori geometrically centred on $t^{*}$, calculated from (4), with a LGSD of $\Delta \cdot n$. Interrupting a test at a time $t_{\text {stop }}$ means the precise value of the failure time $t$ is not exactly known, but lies at $t>t_{\text {stop }}$. From this, we estimate $t$ as the geometric mean of the truncated log-normal distribution, i.e. without the low time range the sample withstood. This is done by centring and reducing $\ln t$ to the standard normal distribution, and integrating:

$$
\begin{aligned}
& \tau=\frac{1}{\Delta \cdot n} \cdot \ln \frac{t}{t^{*}} \text { and } \tau_{\text {stop }}=\frac{1}{\Delta \cdot n} \cdot \ln \frac{t_{\text {stop }}}{t^{*}} \\
& \ln \frac{t}{t^{*}}=\frac{\Delta \cdot n}{\Phi(+\infty)-\Phi\left(\tau_{\text {stop }}\right)} \cdot \int_{\tau_{\text {stop }}}^{+\infty} \phi(\tau) \cdot \tau \cdot d \tau=\frac{\Delta \cdot n \cdot \phi\left(\tau_{\text {stop }}\right)}{1-\Phi\left(\tau_{\text {stop }}\right)}=\Delta \cdot n \cdot \frac{\phi\left(\tau_{\text {stop }}\right)}{\Phi\left(-\tau_{\text {stop }}\right)}
\end{aligned}
$$

Here, $\varphi$ is the standard normal distribution density function (i.e. the derivative of $\Phi$ ), and $1-\Phi\left(\tau_{\text {stop }}\right)$ is replaced by equivalent $\Phi\left(-\tau_{\text {stop }}\right)$ to improve floating-point numerics. Additionally, as 
the test was not complete, these points were only weighted partially, with the weight $w(=1$ for samples where failure was observed) taken to be the probability of failure according to the linear regression:

$$
w=\Phi\left(\tau_{\text {stop }}\right)
$$

As the above-mentioned procedures require a priori knowledge of the fitting parameters $\Delta, \sigma_{0}$ and $n$, the fitting is done iteratively. This is not a problem, as convergence is rapidly achieved due to the small proportion of concerned samples (ca. 1\% reloaded and 1\% stopped overall), and the corresponding change of the parameters, while not negligible, remains moderate.

\subsection{Design stress}

In order to compare materials, we extracted the design stress $\sigma_{d}$ assuming a log-normal distribution, with the following design parameters: lifetime $t_{d}=10$ years and spread allowance $k_{d}=4.75$ (to achieve $\sim 1$ ppm failure probability according to the log-normal distribution):

$$
\sigma_{d}=\sigma_{0} \cdot\left(\frac{t_{d}}{t_{0}}\right)^{-1 / n} \cdot \exp \left(-k_{d} \cdot \Delta\right)
$$

Although, this formula does not take into account the extrapolation error over $1 / \mathrm{n}$, it should yield reasonably conservative values, as, below some stress, slow crack growth essentially ceases, as determined by detailed crack growth experiments [26]. Moreover, in industrial practice, weak devices stemming from gross manufacturing flaws may be quite efficiently sorted out by proof testing [27].

\section{Results and discussions}

The long-term strength data of all variants are given in Tables 3 and 4, and the graphs for selected samples in Fig. 4. The graph for the blank samples includes the regression curve for DuPont (DP) $951 \mathrm{LTCC}$ beams [11] for comparison $(\sigma 0=330 \mathrm{MPa} ; \Delta=12 \% ; \mathrm{n}=28 ; \sigma \mathrm{d}=91 \mathrm{MPa})$.

\subsection{Blank beams (V00)}

Both ZTA variants are far superior to $96 \%$ alumina both in the short term $\left(\sigma_{0}\right)$ and in SCG behaviour $(n)$, which translates into a much higher design stress $\sigma_{d}$, i.e. 572 and $450 \mathrm{MPa}$ for ZTA vs. 240 for $\mathrm{Al}_{2} \mathrm{O}_{3} . \Delta$ is comparable or better for ZTA, in spite of the "experimental" nature of the ZTA grades used here (pilot series). The high $n$ values (170 and 82 vs. 37) indicate they do not contain significant amounts of glassy phase subject to stress corrosion in contact with moisture at room temperature. Accordingly, we also obtained good results with YSZ beams $\left(\sigma_{0}=953 \mathrm{MPa}\right.$; $\Delta=2.0 \% ; n=107 ; \sigma_{d}=640 \mathrm{MPa}$ ) [21]. 
Table 3. Results - parameters for log-normal distribution.

\begin{tabular}{|c|c|c|c|c|c|c|c|c|c|}
\hline \multirow{2}{*}{$\begin{array}{l}\text { Code } \\
\& \\
\text { type }^{\dagger}\end{array}$} & \multicolumn{3}{|c|}{$\mathbf{S 0 0}-\mathbf{A l}_{\mathbf{2}} \mathbf{O}_{3}$} & \multicolumn{3}{|c|}{ S01 - ZTA } & \multicolumn{3}{|c|}{ S03 - ZTA } \\
\hline & $\begin{array}{c}\boldsymbol{\sigma}_{\mathbf{0}} \\
{[\mathrm{MPa}]}\end{array}$ & $\begin{array}{c}\Delta_{\sigma} \\
{[\%]}\end{array}$ & $n$ & $\begin{array}{c}\boldsymbol{\sigma}_{\mathbf{0}} \\
{[\mathrm{MPa}]}\end{array}$ & $\begin{array}{c}\Delta_{\sigma} \\
{[\%]}\end{array}$ & $n$ & $\begin{array}{c}\boldsymbol{\sigma}_{\mathbf{0}} \\
{[\mathrm{MPa}]}\end{array}$ & $\begin{array}{c}\Delta_{\sigma} \\
{[\%]}\end{array}$ & $n$ \\
\hline V00 - & 540 & 6.0 & 37 & 720 & 2.4 & 170 & 750 & 5.6 & 82 \\
\hline V01 Ag & 510 & 5.2 & 49 & 790 & 3.8 & 141 & 700 & 4.8 & 132 \\
\hline V02 Ag & 590 & 5.4 & 35 & 810 & 7.3 & 67 & 710 & 4.0 & 99 \\
\hline V03 $\mathrm{Ag}^{\#}$ & 480 & 4.4 & 34 & 620 & 10.3 & 41 & 630 & 6.3 & 40 \\
\hline V04 Ag ${ }^{\S}$ & 520 & 5.4 & 45 & 780 & 6.8 & 59 & 700 & 4.9 & 73 \\
\hline V05 Au & 500 & 4.9 & 50 & 690 & 4.5 & 128 & 700 & 4.6 & 116 \\
\hline V06 Au & 510 & 5.7 & 47 & 870 & 7.3 & 125 & 710 & 2.9 & 197 \\
\hline V07 R & 510 & 5.6 & 54 & 870 & 8.4 & 66 & 700 & 3.5 & 261 \\
\hline V08 R & 570 & 5.8 & 40 & 910 & 6.8 & 35 & 710 & 4.2 & 105 \\
\hline V09 D & 540 & 6.4 & 63 & 770 & 3.3 & 68 & 700 & 4.1 & 81 \\
\hline V10 G & 530 & 6.4 & 65 & 790 & 4.7 & 113 & 680 & 5.6 & 179 \\
\hline V11 G & 530 & 6.0 & 57 & 900 & 7.6 & 52 & 700 & 5.4 & 119 \\
\hline V12 AgG & 610 & 5.5 & 48 & 850 & 7.7 & 65 & 710 & 5.2 & 115 \\
\hline V13 $\mathrm{AgG}^{\#}$ & 490 & 12.1 & 23 & 730 & 10.4 & 22 & 700 & 11.2 & 20 \\
\hline $\mathrm{V} 14 \mathrm{AgG}^{\S}$ & 550 & 6.8 & 40 & 900 & 9.1 & 35 & 760 & 5.8 & 47 \\
\hline V15 AuG & 540 & 6.6 & 49 & 960 & 10.6 & 34 & 734 & 4.7 & 81 \\
\hline V16 AuG & 550 & 5.1 & 71 & 870 & 9.0 & 60 & 715 & 5.3 & 82 \\
\hline V17 RG & 570 & 7.1 & 55 & 860 & 7.8 & 47 & 735 & 6.3 & 60 \\
\hline V18 RG & 500 & 4.7 & 54 & 810 & 4.8 & 32 & 654 & 6.1 & 58 \\
\hline
\end{tabular}

$\uparrow \mathrm{Ag}=$ Ag-based conductor; $\mathrm{Au}=\mathrm{Au}$ conductor; $\mathrm{R}=$ resistor; $\mathrm{D}=$ dielectric $; \mathrm{G}=$ overglaze.

$\$$ nominally unalloyed $\mathrm{Ag}$

\# $\mathrm{Ag}: \mathrm{Pd} \approx 3: 1$, heavily fritted

$\S \mathrm{Ag}: \mathrm{Pd}: \mathrm{Pt} \approx 90: 6: 4 \mathrm{wt} \%$ 
Table 4. Results - parameters for Weibull distribution $\sigma_{W} \& m^{*}$, and design stress $\sigma_{d}$.

\begin{tabular}{|c|c|c|c|c|c|c|c|c|c|}
\hline \multirow{2}{*}{$\begin{array}{l}\text { Code } \\
\text { \& } \\
\text { type }^{\dagger}\end{array}$} & \multicolumn{3}{|c|}{$\mathbf{S 0 0}-\mathbf{A l}_{\mathbf{2}} \mathbf{O}_{3}$} & \multicolumn{3}{|c|}{ S01 - ZTA } & \multicolumn{3}{|c|}{ S03 - ZTA } \\
\hline & $\begin{array}{c}\boldsymbol{\sigma}_{W} \\
{[\mathrm{MPa}]}\end{array}$ & $m^{*}$ & $\begin{array}{c}\sigma_{d} \\
{[\mathrm{MPa}]}\end{array}$ & $\begin{array}{c}\boldsymbol{\sigma}_{W} \\
{[\mathrm{MPa}]}\end{array}$ & $m^{*}$ & $\begin{array}{c}\boldsymbol{\sigma}_{\boldsymbol{d}} \\
{[\mathrm{MPa}]}\end{array}$ & $\begin{array}{c}\boldsymbol{\sigma}_{W} \\
{[\mathrm{MPa}]}\end{array}$ & $m^{*}$ & $\begin{array}{c}\boldsymbol{\sigma}_{\boldsymbol{d}} \\
{[\mathrm{MPa}]}\end{array}$ \\
\hline V00 - & 555 & 19 & 240 & 729 & 46 & 572 & 767 & 20 & 450 \\
\hline V01 $\mathrm{Ag}^{\$}$ & 519 & 21 & 265 & 804 & 30 & 573 & 718 & 23 & 482 \\
\hline V02 $\mathrm{Ag}^{\$}$ & 601 & 21 & 259 & 840 & 16 & 430 & 728 & 28 & 486 \\
\hline V03 $\mathrm{Ag}^{\#}$ & 488 & 26 & 219 & 654 & 11 & 237 & 647 & 19 & 287 \\
\hline V04 Ag ${ }^{\S}$ & 530 & 20 & 257 & 808 & 17 & 409 & 717 & 23 & 424 \\
\hline V05 Au & 514 & 24 & 269 & 706 & 24 & 479 & 718 & 25 & 477 \\
\hline V06 Au & 527 & 20 & 258 & 901 & 16 & 525 & 720 & 36 & 559 \\
\hline V07 R & 523 & 21 & 271 & 904 & 14 & 433 & 709 & 31 & 548 \\
\hline V08 R & 589 & 20 & 267 & 944 & 17 & 376 & 728 & 25 & 484 \\
\hline V09 D & 556 & 18 & 292 & 784 & 32 & 492 & 710 & 28 & 449 \\
\hline V10 G & 542 & 18 & 288 & 806 & 24 & 530 & 699 & 20 & 468 \\
\hline V11 G & 545 & 19 & 281 & 936 & 16 & 432 & 723 & 21 & 463 \\
\hline V12 $\mathrm{AgG}^{\$}$ & 624 & 21 & 311 & 884 & 16 & 428 & 726 & 21 & 466 \\
\hline V13 $\mathrm{AgG}^{\#}$ & 515 & 10 & 115 & 764 & 11 & 185 & 736 & 10 & 156 \\
\hline $\mathrm{V} 14 \mathrm{AgG}^{\S}$ & 568 & 16 & 244 & 943 & 13 & 334 & 780 & 20 & 381 \\
\hline V15 AuG & 558 & 17 & 266 & 1'011 & 11 & 325 & 751 & 24 & 460 \\
\hline V16 AuG & 559 & 22 & 325 & 906 & 13 & 408 & 734 & 22 & 438 \\
\hline V17 RG & 589 & 16 & 285 & 893 & 154 & 393 & 757 & 18 & 393 \\
\hline V18 RG & 510 & 25 & 277 & 833 & 24 & 351 & 673 & 19 & 349 \\
\hline
\end{tabular}

$\dagger \mathrm{Ag}=\mathrm{Ag}$-based conductor; $\mathrm{Au}=\mathrm{Au}$ conductor; $\mathrm{R}=$ resistor; $\mathrm{D}=$ dielectric $; \mathrm{G}=$ overglaze.

$\$$ nominally unalloyed $\mathrm{Ag}$

\# $\mathrm{Ag}: \mathrm{Pd} \approx 3: 1$, heavily fritted

$\S \mathrm{Ag}: \mathrm{Pd}: \mathrm{Pt} \approx 90: 6: 4 \mathrm{wt} \%$ 

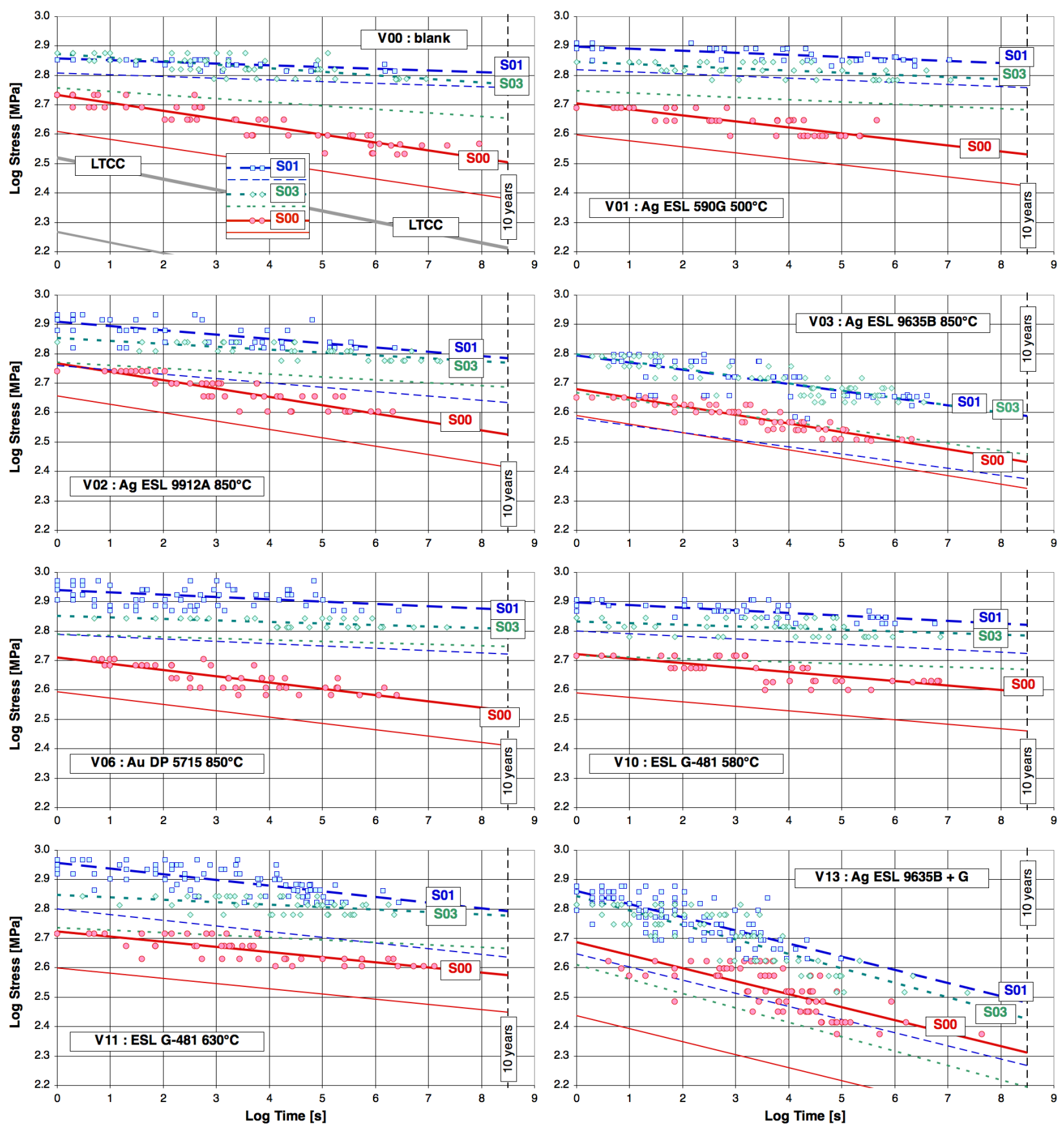

Figure 4. Selected results. For each series, both the regression line (through the labels) and the designstress line, shifted down by $4.75 \cdot \Delta / \ln (10)$, are shown. 


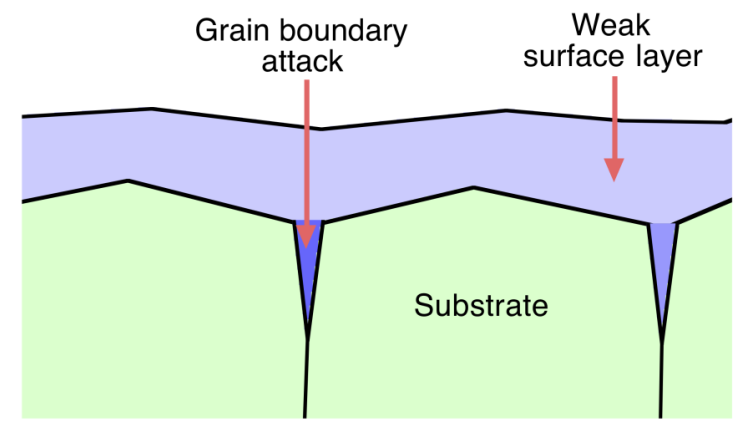

Figure 5. Purported mechanisms of strength degradation.

Better stress corrosion resistance could also be obtained with alumina by employing higher purity, but the processing is more involved [25], and the strength remains lower than that of ZTA. These results essentially agree with other work [26]. Conversely, LTCC material, which is more glassy and contains lower-melting glasses (which tend to have a higher affinity for water), expectedly performs even worse (see above). As LTCC is often used in sensors [11,13,15-17], further attention to its mechanical properties is warranted, although study is rendered difficult by the many specific and proprietary compositions, and possibly significant processing dependence of the mechanical properties.

\subsection{Effect of single thick-film compositions (V01-V11)}

The advantage of ZTA (and of YSZ as well [22]) may be strongly reduced by the presence of thickfilm layers on the tensile side; one can see in Tables 3 and 4, as well as in Fig. 4, that some layers mainly affect the long-term strength. Apparently, their interaction with the substrate leads to facilitated crack propagation in static fatigue conditions, at the surface and/or in the grain boundaries (Fig. 5). Metallic layers should not lead to such phenomena, but thick-film conductors contain glass frits and/or reactive oxides such as $\mathrm{Bi}_{2} \mathrm{O}_{3}$ and $\mathrm{CuO}_{\mathrm{x}}$ to impart adhesion to the substrate [27-31]. Obviously, the static fatigue behaviour of these different compounds and reaction products strongly differs:

- Standard Au (V06), thin Au (V05) and low-firing Ag (V01) conductors have little marked effect on SCG behaviour, and may be used without restriction. On alumina, these three compositions actually seem to improve SCG behaviour, which could be due to some protective effect of the surface (less access from humidity), coupled with a thermal tensile pre-stress in the layers, which partially counteracts the bending moment imposed by the testing apparatus.

- Common fritless or mixed Ag-rich conductors (V02 and V04) have no significant effect on $\mathrm{Al}_{2} \mathrm{O}_{3}$, but slightly degrade $\mathrm{SCG}$ of one type of ZTA, S01.

- Heavily fritted Pd-rich Ag:Pd conductors (V03) have a deleterious effect, which is limited on $\mathrm{Al}_{2} \mathrm{O}_{3}$ but catastrophic on ZTA, lowering $n$ down to values typical for alumina, i.e. ca. 40 .

- Resistors, dielectrics and overglazes (V07-V11) have complex effects, ranging from apparent improvement of SCG resistance (e.g. V07 and V09-11 on alumina) to strong degradation (e.g. V08 on ZTA grade S01). As in the case of some conductors, the apparent positive effect seen on 
alumina may be explained by protection of part of the surface, with the layers themselves being probably protected at low stresses by compressive matching on the alumina substrate.

- Overglazing the substrate at higher temperature (V11 vs. V10) tends to degrade $\mathrm{n}$ somewhat for ZTA, with a stronger effect seen on type S01.

The more marked effects seen on ZTA are expected, as the blank substrates have very good SCG performance. On the other hand, thick-film grade $\mathrm{Al}_{2} \mathrm{O}_{3}$, which contains some obviously SCGsensitive glass phase, is inherently weak, which explains it being affected only in the most severe cases, e.g. Ag:Pd conductors. Interestingly, both ZTA grades are not strictly equivalent: S03 has a lower initial strength, but tends to maintain a lower SCG sensitivity with layers than S01; this is especially visible for the resistor compositions (V07 and V08), but also seen with other layers, e.g. V02, V04 and V11.

Comparing V01 vs. V03 (fritted conductors) and V10 vs. V11 (overglazing), one can see that a higher degree of layer-substrate reaction, as promoted by higher firing temperatures, tends to degrade SCG performance. However, the nature of the deposited glass also plays a role, as the lowfiring resistor composition (V08) tends to degrade SCG more than the high-firing one (V07). In this case, this may be expected from the higher thermal expansion (i.e. more tensile stress) and lower corrosion performance (more SCG susceptibility) of low-melting glasses [32].

In this light, the especially deleterious effect on strength seen with heavily alloyed Ag:Pd conductor pastes is elucidated as not directly stemming from the metallurgy itself, but from the considerable amounts of glass frit and reactive oxides present in these formulations, together with the high $850^{\circ} \mathrm{C}$ firing temperature, both additives and temperature being helpful in ensuring strong and reliable adhesion on different nuances of industrial alumina substrates [27-29]. The presence of glass frit also promotes sintering of the higher-melting (vs. pure Ag) Ag:Pd alloys [28,30].

To confirm this interpretation, a small complementary microscopic/microprobe analysis was carried out on two conductor pellets, V03 (fritted heavily alloyed Ag:Pd) and V04 (fritless Ag with low $\mathrm{Pd}+\mathrm{Pt}$ content), using the same methods as previous work [31]. Fired V03 pellets expectedly exhibited a large amount $(\approx 16 \%$ vol. $\%)$ of glassy phase, based on lead-bismuth borosilicate glass with $\mathrm{ZnO}$ and $\mathrm{Al}_{2} \mathrm{O}_{3}$ additions $\left(\mathrm{B}_{2} \mathrm{O}_{3}\right.$ not detectable by our analysis, but assumed from literature [27-29]), and an $\mathrm{Ag}: \mathrm{Pd}$ ratio of $\approx 3: 1$. In contrast, no significant glassy regions are visible for $\mathrm{V} 04$, which, on the other hand, contains particles rich in $\mathrm{CuO}_{\mathrm{x}}$, with some $\mathrm{Bi}_{2} \mathrm{O}_{3}$ also present, these oxides, together with a small amount of $\mathrm{CdO}$ (1-1.5\% in V04 according to the supplier, not detected in our analysis) being the typical additives for reactive oxide bonding [27-29]. Also, in accordance to expectations, the metallic content in V04 was much closer to pure Ag, ca. $90 \mathrm{Ag}+$ $6 \mathrm{Pd}+4 \mathrm{Pt}$ by weight.

It is interesting to compare V03 $=$ ESL $9635 \mathrm{~B}$ to our previous results on the nominally equivalent DP 9473 ink [31]. For DP 9473, we obtained similar results ( $\approx 18$ vol.\% glass, $\mathrm{Ag}: \mathrm{Pd} \approx 3: 1)$ to V03, the main difference lying in the glassy phase being lead-free, i.e. containing only $\mathrm{Bi}_{2} \mathrm{O}_{3}$ as a heavy metal oxide, its composition being otherwise comparable.

\subsection{Overglazed layers (V12-V18)}

Globally, overglazing effects a further degradation to the SCG performance, with in many cases a synergistic effect: performance is lower than with the original layer or the overglaze alone. This is particularly evident for the Ag:Pd conductor (V13), where overglazing results in very poor SCG behaviour for all substrates. Evidently, such a combination, which is often found in thick-film electronics (solder/bond parts, with adjacent areas overglazed), requires careful design to avoid areas potentially subjected to stresses. 
The other compositions confirm the trends seen for the single layers, including the apparently lower sensitivity of ZTA S03 vs. S01 to the presence of layers. In terms of design stress $\sigma_{d}$, the advantage of using ZTA vs. $\mathrm{Al}_{2} \mathrm{O}_{3}$, while still present, is further reduced in many cases.

\section{Conclusions and outlook}

In this study, the effect of various thick-film layers on long-term strength in moist air (ca. 100\% $\mathrm{RH}$ ) of ceramic $96 \%$ alumina and ZTA beams was analysed. In the blank state, ZTA allows more than doubling ( $\mathrm{S} 01)$ of the design stress over a 10-year period. This is due to higher strength and especially much lower SCG sensitivity, associated with both studied variants of this material and stemming from the essential absence of glassy phase. ZTA is preferred over glass-free $\mathrm{Al}_{2} \mathrm{O}_{3}$ [25] due to its higher strength brought about by the $\mathrm{ZrO}_{2}$ reinforcing phase, and ZTA nanocomposites were found to outperform both $\mathrm{Al}_{2} \mathrm{O}_{3}$ and $\mathrm{YSZ}$ in static fatigue resistance [26].

However, high-strength ZTA and YSZ are in general more susceptible to degradation by the presence of surface layers than is the case for "weaker" $96 \% \mathrm{Al}_{2} \mathrm{O}_{3}$, which has important implications for circuit design. One obviously advantageous application for ZTA is therefore simple cantilever [12] or ring-on-ring [14] force sensors: a single-side, lower-cost design may be used, with the other side, under tensile stress, left blank. This greatly simplifies manufacturing (no vias or matched multiple resistor depositions), and the resulting signal penalty (only 2 out of 4 resistors active) is more than compensated by the higher allowable strain. In most cases, ZTA is preferable to YSZ, due to its lower cost and better compatibility with standard thick-film compositions [18].

The very deleterious effect on SCG performance of standard Ag:Pd (ratio ca. 3:1) fritted conductors used for bond / solder pads was confirmed, with even much worse behaviour found when overglazing such conductors (in practice unavoidable). Mechanical sensors or any circuits subjected to significant loads should therefore be designed to keep such pads away from zones possibly subjected to high tensile stresses. Alternatively, going to a clad system, consisting of an Ag thickfilm process with subsequent chemical coating of pads by a $\mathrm{Ni}-\mathrm{Au}$ sequence, should avoid issues with Ag:Pd conductors while improving other manufacturing [33] and reliability aspects in harsh environments [34].

Several conductive compositions offer little or no apparent reduction of strength, and therefore can be essentially used without restriction: both $\mathrm{Au}$ conductors and the low-temperature Ag. Other compositions such as Ag-rich conductors resistors give intermediate results: strength is somewhat lowered on ZTA, but not on alumina.

The trends observed in strength degradation hint at the mechanism being formation of SCGsensitive layers on the substrate surface, which act as sites for initiation of cracks that can then propagate into the substrate. However, this hypothesis should be confirmed by more detailed studies, such as controlled crack growth experiments [26], coupled with elucidation of the nature of the interactions between substrate and thick films, with the goal of reducing the observed strength degradation - or even inducing strength improvements [35,36].

Besides static fatigue, the effect of thick films on other aspects, such as the threshold levels for subcritical crack growth [26] and cyclic fatigue [37,38] should also be investigated. For SCG, switching from purely static to constant-rate (dynamic) loading tests [20] is desirable, as such tests obviate the problem of early failures and surviving samples and the corresponding complex data analysis. 


\section{Acknowledgements}

The authors gratefully acknowledge help from G. Corradini, M. Garcin and H. Birol with setup, sample preparation and microscopy/analysis, CeramTec AG (Marktredwitz, Germany) for providing the ZTA substrates, as well as financing from the Swiss CTI Innovation Promotion Agency (grants \#4300.1 “TEPLAZID” \& \#6620.1 “HITCLES”), and from the EU FP7 (grant ACP8-GA-2009-234119, “CREAM”).

\section{References}

[1] U. Chowdhry, A.W. Sleight, Ceramic substrates for microelectronic packaging, Annual Review of Materials Science 17 (1987) 323-340.

[2] R.R. Tummala, Ceramics in microelectronic packaging, Advances in Ceramics 26 (1989) 3-16.

[3] A. Roosen, Entwicklungspotentiale keramischer Substratwerkstoffe (Development potential of ceramic substrate materials), in: IMAPS Deutschland Konferenz, 1999.

[4] L.E. Khoong, Y.M. Tan, Y.C. Lam, Overview on fabrication of three-dimensional structures in multi-layer ceramic substrate, Journal of the European Ceramic Society 30 (2010) 1973-1987.

[5] N.M. White, Thick film technology, in: M. Prudenziati (Ed.), Handbook of Sensors and Actuators, vol. 1: Thick Film Sensors, Elsevier, 1994, pp. 3-33.

[6] J.F. Burgess, C.A. Neugebauer, G. Flanagan, R.E. Moore, The direct bonding of metals to ceramics and application in electronics, Electrocomponent Science and Technology 2 (1976) 233-240.

[7] D. Belavič, M. Hrovat, M. Santo-Zarnik, J. Cilenšek, J. Kita, L. Golonka, A. Dziedzic, W. Smetana, H. Homolka, R. Reicher, Benchmarking different substrates for thick-film sensors of mechanical quantities, in: Proc. $15^{\text {th }}$ Eur. Microelectron. Packaging Conf. (EMPC), Brugge (BE), IMAPS, 2005, pp. 216-221.

[8] N.M. White, J.D. Turner, Thick-film sensors: past, present and future, in: Proc. $14^{\text {th }}$ Int. Conf. on Solid-State Sensors, Actuators and Microsystems - Transducers / Eurosensors'07, Lyon (FR), 2007, pp. 107-111.

[9] C. Jacq, T. Maeder, P. Ryser, High-strain response of piezoresistive thick-film resistors on titanium alloy substrates, Journal of the European Ceramic Society 24 (2004) 1897-1900.

[10] T. Maeder, C. Jacq, P. Ryser, Low-firing thick-film piezoresistive sensors for medical instruments, Sensors and Actuators, 172 (2011) 228-232.

[11] H. Birol, M. Boers, T. Maeder, G. Corradini, P. Ryser, Design and processing of low-range piezoresistive LTCC force sensors, in: Proc., XXIX International Conference of IMAPS Poland, Koszalin, 2005, pp. 385-388.

[12] T. Maeder, V. Fahrny, S. Stauss, G. Corradini, P. Ryser, Design and characterisation of low-cost thick-film piezoresistive force sensors for the $100 \mathrm{mN}$ to $100 \mathrm{~N}$ range, in: Proc., XXIX Int. Conf. of IMAPS Poland, Koszalin, 2005, pp. 429-434.

[13] H. Birol, T. Maeder, I. Nadzeyka, M. Boers, P. Ryser, Fabrication of a millinewton force sensor using low temperature co-fired ceramic (LTCC) technology, Sensors and Actuators A 134 (2007) 334-338.

[14] T. Maeder, G. Affolter, N. Johner, G. Corradini, P. Ryser, Optimisation of a thick-film $10 . . .400$ N force sensor, Microelectronics Reliability 48 (2008) 902-905.

[15] U. Partsch, D. Arndt, H. Georgi, A new concept for LTCC-based pressure sensors, in: Proc., $3^{\text {rd }}$ Int. Conf. on Ceramic Interconnect and Ceramic Microsystems Technologies (CICMT), Denver (USA), 2007, THA23.

[16] Y. Fournier, T. Maeder, G. Boutinard-Rouelle, A. Barras, N. Craquelin, P. Ryser, Integrated LTCC pressure / flow / temperature multisensor for compressed air diagnostics, Sensors 10 (2010) 11156-11173.

[17] T. Maeder, Y. Fournier, J.-B. Coma, N. Craquelin, P. Ryser, Integrated SMD pressure/flow/temperature multisensor for compressed air in LTCC technology: thermal flow and temperature sensing, Microelectronics Reliability 51 (2011) 1245-1249.

[18] T. Maeder, C. Jacq, H. Birol, P. Ryser, High-strength ceramic substrates for thick-film sensor applications, in: Proc., $14^{\text {th }}$ Eur. Microelectronics and Packaging Conf., IMAPS, Friedrichshafen (DE), 2003, pp. $133-137$.

[19] R. Adams, P.W. McMillan, Review - static fatigue in glass, Journal of Materials Science 12 (1977) $643-657$. 
[20] S.R. Choi, M. Powers, N.N. Nemeth, Slow crack growth behavior and life / reliability analysis of 96 wt \% alumina at ambient temperature with various specimen / loading configurations, report TM-2000-210206, NASA, Glenn Research Center (USA), 2000.

[21] T. Maeder, H. Birol, C. Jacq, P. Ryser, Strength of ceramic substrates for piezoresistive thick-film sensor applications, in: Proc. Eur. Microelectronics and Packaging Symp, Prague (CZ), 2004, pp. 272-276.

[22] T. Maeder, C. Jacq, G. Corradini, P. Ryser, Effect of thick-film materials on the mechanical integrity of highstrength ceramic substrates, in: Proc. $15^{\text {th }}$ Eur Microelectronics and Packaging Conf. (EMPC), Brugge (BE), IMAPS, 2005, pp. 377-381.

[23] G.A. Gogotsi, V.P. Zavada, Evaluation of the life of ceramics from subcritical crack growth parameters, Strength of Materials 17 (1985) 210-214.

[24] B.T. Lü, Fatigue strength prediction of soda-lime glass, Theoretical and Applied Fracture Mechanics 27 (1997) 107-114.

[25] A. Krell, E. Pippel, J. Woltersdorf, W. Burger, Subcritical crack growth in $\mathrm{Al}_{2} \mathrm{O}_{3}$ with submicron grain size, Journal of the European Ceramic Society 23 (2003) 81-89.

[26] A.H. De Aza, J. Chevalier, G. Fantozzi, M. Schehl, R. Torrecillas, Crack growthresistance of alumina, zirconia and zirconia toughened alumina ceramics for joint prostheses, Biomaterials 23 (2003) 937-945.

[27] M. Monneraye, Les encres sérigraphiables en microélectronique hybride: les matériaux et leur comportement (Screenable inks in hybrid microelectronics: the materials and their behaviour), Acta Electronica 21 (1978) 263--281.

[28] S.F. Wang, J.P. Dougherty, W. Huebner, Silver-palladium thick-film conductors, Journal of the American Ceramic Society 77 (1994) 3051-3072.

[29] B.E. Taylor, J.J. Felten, J.R. Larry, Progress in and technology of low-cost silver containing thick-film conductors, in: IEEE Trans. Comp. Hyb. Manuf. Technol. CHMT-3 (1980), pp. 504-517.

[30] S.S. Cole, Sintering of Ag-Pd in the presence of a reactive glass, Journal of the American Ceramic Society 55 (1972) 296-299.

[31] H. Birol, T. Maeder, P. Ryser, Influence of processing and conduction materials on properties of co-fired resistors in LTCC structures, Journal of the European Ceramic Society 26 (2006) 1937-1941.

[32] I.L. Trubnikov, Thermal expansion and corrosion behavior of lead-borosilicate glasses, Refractories and Industrial Ceramics 41 (2000) 169-171.

[33] A. Kipka, C. Modes, Q. Reynolds, M. Neidert, S. Malkmus, F. Gora, Self-constrained sintering LTCC - a reliable solution for automotive electronic application, in: Proc. $1^{\text {st }}$ Int. Conf. on Ceram. Interconnect and Ceram. Microsyst. Technol. (CICMT), Baltimore (USA), 2005, MP42.

[34] R. Johannessen, F. Oldervoll, F. Strisland, High temperature reliability of aluminium wire-bonds to thin film, thick film and low temperature co-fired ceramic (LTCC) substrate metallization, Microelectronics Reliability 48 (2008) 1711-1719.

[35] P.F. James, M. Chen, F.R. Jones, Strengthening of soda-lime-silica glass by sol-gel- and melt-derived coatings, Journal of Non-Crystalline Solids 155 (1993) 99-109.

[36] I.W. Donald, Methods for improving the mechanical properties of oxide glasses, Journal of Materials Science 24 (1989) 4177-4208.

[37] K. Duan, Y.W. Mai, B. Cotterell, Cyclic fatigue of a sintered $\mathrm{Al}_{2} \mathrm{O}_{3} / \mathrm{ZrO}_{2}$ ceramic, Journal of Materials Science 30 (1995) 5192-5198.

[38] F. Guiu, M.J. Reece, D.A.J. Vaughan, Cyclic fatigue of ceramics, Journal of Materials Science 26 (1991), 3275--3286. 


\section{Appendix A. Comparison of Weibull and log-normal distributions}

A comparison of both distributions is given, in logarithmic space, in Fig. 6, with the Weibull parameters adjusted to give the same geometric mean and standard deviation as the standard lognormal distribution (Erreur ! Des objets ne peuvent pas être créés à partir des codes de champs de mise en forme. $=\operatorname{LGSD}_{\mathrm{x}}=1$ ). One sees that the Weibull distribution has a larger fraction at low values, compensated by a maximal density at a value above the geometric mean. Also, the high-end cutoff is much sharper. The above graph can be scaled to give the corresponding relations for our fitting parameters:

Erreur ! Des objets ne peuvent pas être créés à partir des codes de champs de mise en forme. and Erreur ! Des objets ne peuvent pas être créés à partir des codes de champs de mise en forme.

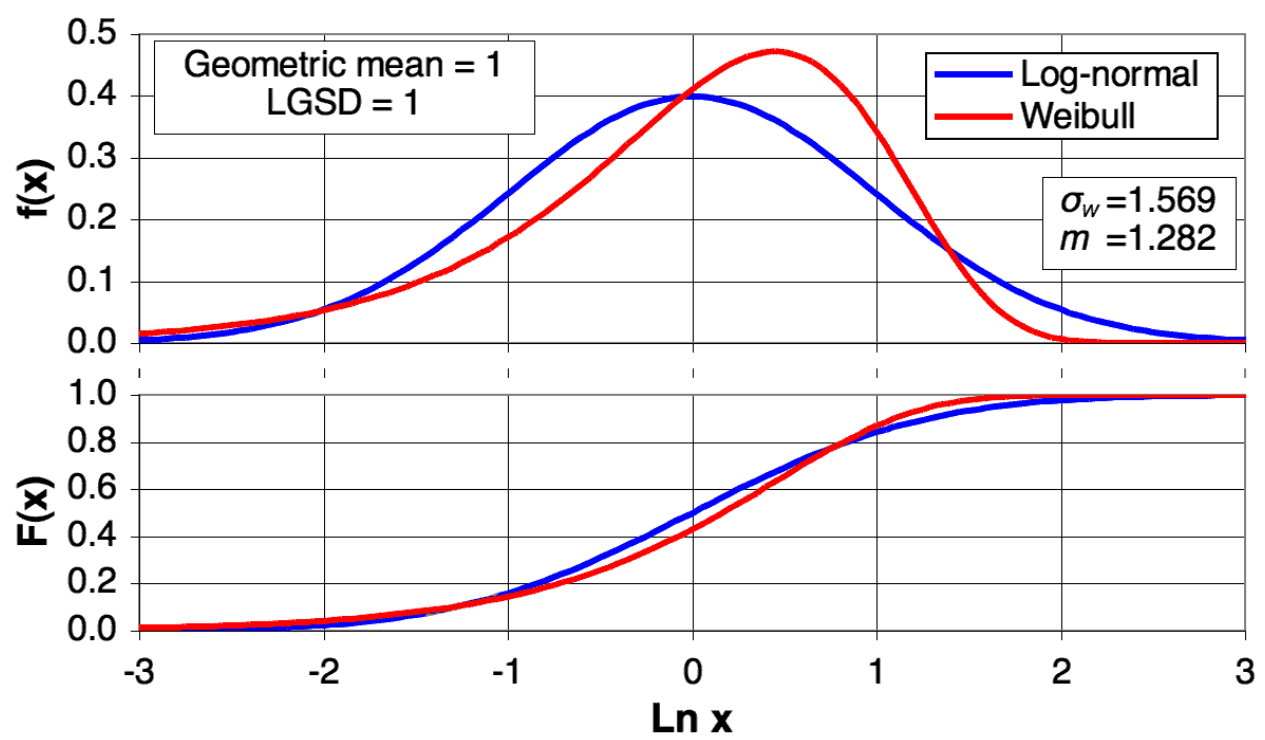

Figure 6. Weibull vs. log-normal distribution, with same geometric mean and standard deviation. $f=$ probability density function; $F=$ cumulative probability function . 


\section{Biographies}

Thomas Maeder graduated at the Ecole Polytechnique Fédérale de Lausanne (EPFL) in materials science, and continued with a $\mathrm{PhD}$ in piezoelectric thin films, then a post-doc at IBM Rüschlikon in single-crystal conductive oxides. He now heads the thick-film technology group at the EPFL, where current areas of interest are thick-film and LTCC technology for advanced sensor, packaging, biomedical and harsh-environment applications.

Caroline Jacq graduated with a Master thesis in materials science from the Institut Supérieur des Matériaux du Mans (ISMANS), and is working as a researcher at the Ecole Polytechnique Fédérale de Lausanne (EPFL) since 2001. Her main research interests concern the development and study of novel lead-free thick-film materials systems and their application to medical devices.

Peter Ryser received a Master degree in Physics (University Neuchâtel 1979), a PhD in applied Physics (University Geneva 1985) and a masters degree in Corporate Management (Lucerne 1993). His professional background includes several R\&D activities. From 1990-1998 he was the head of research at Siemens Building Technologies. Since 1999 Peter Ryser is professor at the Swiss Federal Institute of Technology EPFL in Lausanne and act as a director for the micro engineering section. 